\title{
A Novel Asymmetrical-Pole PS-DSPM with Variation of Outer Stator Teeth Number for An Improvement of Electromagnetic Performances
}

\author{
Warat Sriwannarat ${ }^{1}$, Pirat Khunkitti ${ }^{2}$, Pattasad Seangwong ${ }^{3}$, Natakorn Thasnas $^{4}$ and Apirat Siritaratiwat $^{5, *}$ \\ ${ }^{1,4}$ Department of Electrical and Computer Engineering, Kasetsart University Chalermphakiet, Sakon Nakhon Province Campus, \\ Sakon Nakhon 47000, Thailand. \\ ${ }^{2,3,5}$ Department of Electrical Engineering, Faculty of Engineering, Khon Kaen University, Khon Kaen 40002, Thailand.
}

\begin{abstract}
The asymmetrical-pole ratio installed in the partitioned stator doubly salient permanent magnet machine (PS-DSPM) is proposed. Its particular outer stator teeth number is varied to improve the electromagnetic performances. The electromagnetic indicators including the magnetic flux distribution, magnetic flux linkage, back-electromotive force (back-EMF), cogging torque, electromagnetic torque, and ripple torque are investigated and then, compared with the conventional PS-DSPM by finite element analysis simulation. The results illustrate that the symmetrical distribution of the magnetic flux firstly is achieved by all proposed machines. The flux linkage magnitude is increased due mainly to the increase of the magnetic flux paths and winding slots when the increased outer stator teeth number. Especially, we found that the asymmetrical-pole PS-DSPM with 30 outer stator teeth has the suitable outer stator teeth number since it can produce the higher back-EMF waveform with a robust outer stator structure than the other proposed machines as well as a conventional machine. Moreover, the average electromagnetic torque with small ripple torque is reached by this proposed machine, which is $39.29 \%$ enhanced from the conventional one under the same copper loss. Hence, the asymmetrical-pole PS-DSPM having 30 outer stator teeth is the novel alternative machine for PSDSPM improvement.
\end{abstract}

Keywords: Asymmetrical-pole ratio, partitioned stator, PSDSPM, outer stator teeth number, electromagnetic performances

\section{INTRODUCTION}

Permanent magnet (PM) machines have been extensively researched in the past decades because of their outstanding benefits including high reliability, structural robustness, high flux linkage, high back-electromotive force (back-EMF), and high torque characteristics without the field excitation copper loss [1], [2]. According to the location of PMs in the PM machines, they can be categorized into two main types, which are the PMs embedded at stator structure calling the stator-PM machine and the PMs installed at the rotor structure calling the rotor-PM machine [3]. The stator-PM machines are widely studied in many researches since their machine structures have a low weight and small inertia at their rotor [4], [5]. These machines are classified into three main categories according to the PM location in the stator structure e.g. the PMs mounted surface on the teeth in the flux-reversal PM machine, the PMs inserted in the teeth in the flux-switched PM machine, and the
PMs instated in the yoke in doubly salient PM (DSPM) machine [6]-[8]. Particularly, the DSPM machines improved from the switched reluctance machines has many remarkable advantages over the other PM machines such as simple configuration, robustness structure, a direct-drive without gearbox and high torque density [9]-[11]. Several researches have proposed the partitioned-stator (PS) technique applied in the stator-PM machines [12], [13]. The significant property of this technique is the reduction of the magnetic deterioration because the PMs in the stator-PM machine are separated from the heat produced by the armature winding [14], [15]. Nowadays, the DSPM machines with adding the PS technique (PS-DSPM) have been presented in several studies [16], [17]. The machine properties of the PS-DSPM structure are reported in [18]. Additionally, the pole configurations in PS-DSPM consisting of the stator tooth, the rotor pole and the PM number, are an important factor for the influence on the electromagnetic performances [19], [20]. Many studies have presented the development of these pole configurations for improving the PSDSPM however, the pole configurations must be simultaneously varied as the symmetrical-pole ratio [21]. Therefore, the magnetic gear machine with the flux-modulated double rotor has the novel pole configuration as the asymmetrical-pole ratio [22]. The qualification of this pole configuration is the improvement of electromagnetic performances by varying the particular outer stator teeth number.

Then, this paper aims to propose the PS-DSPM adding the novel asymmetrical-pole ratio. The particular outer stator teeth number of this machine is varied to verify the suitable outer stator structure for improving the electromagnetic performances. The initial electrical indicators including the magnetic flux distribution, magnetic flux-linkage, and backEMF are analyzed. The cogging torque, electromagnetic torque, and ripple torque are demonstrated and then, compared with the conventional PS-DSPM. The simulation results are based on the two-dimensional finite element method.

\section{MACHINE TOPOLOGY DESIGN}

The conventional PS-DSPM with 12/10/12-pole (outer stator teeth/rotor iron pieces/PM pieces-pole) was introduced by Z.Z. Wu [18]. In this paper, the conventional PS-DSPM is installed by the new pole configuration as the asymmetricalpole ratio initiated by N. Fernanda [22]. The asymmetrical-pole PS-DSPM is proposed, which its structure is comprised of 12 teeth of outer stator wound by the singer layer winding coil, 8 pieces of rotor iron without brush, winding coil and PM for the 
weight and inertia reduction, and 14 pieces of PM made by $\mathrm{Nd}-\mathrm{Fe}-\mathrm{B}$ material at inner stator (12/8/14-pole) as indicated in Fig. 1(a). In addition, the outer stator teeth number variation of this machine is further investigated for improving the electromagnetic performances. The number of outer stator teeth is varied based on $12+6 n$ teeth ratio, in which $n$ is 0 to 4 . The number of $n$ is not able to be increased over four because of a limitation of the outer stator teeth area in this machine. The cross-section of the asymmetrical-pole PS-DSPM with the varied outer stator teeth number as following 18, 24, 30, 36 teeth is illustrated in Fig. 1(b)-(e). However, the rotor iron piece and PM of these proposed machines are determined to be fixed as 8 pieces and 14 pieces, respectively, in order to study particularly the variation of outer stator teeth number. The outer stator teeth parameters of each proposed machine are precisely designed by the numerical linear order method [19]. The designed outer stator teeth parameters and also, the other structural parameters of all proposed machines are indicated in Table 1 .

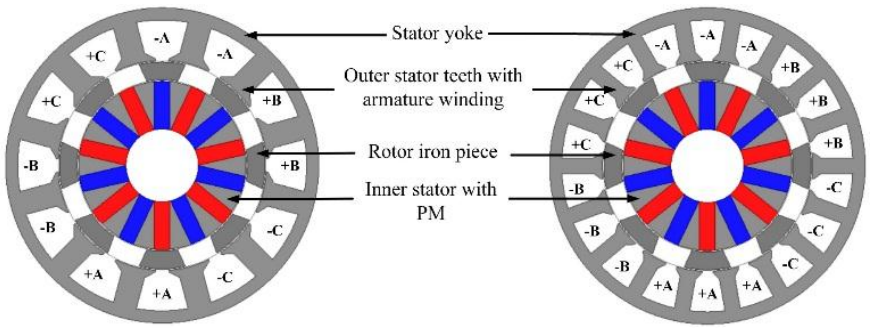

(a)

(b)

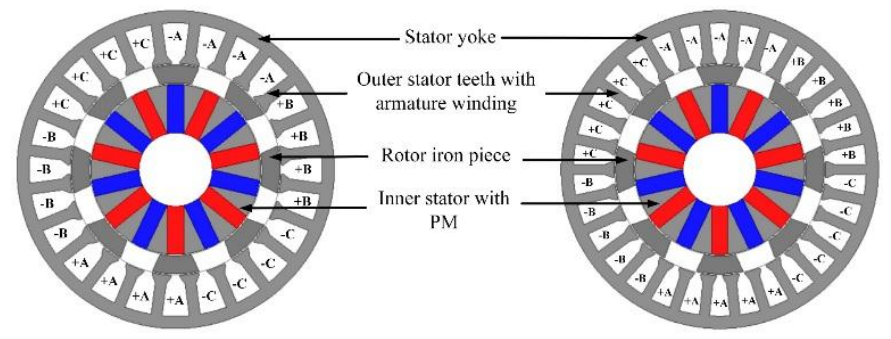

(c)

(d)

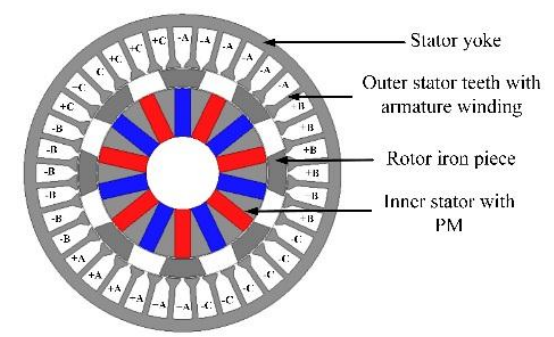

(e)

Fig. 1. The cross-section of the asymmetrical-pole PS-DSPM with: (a) 12, (b) 18, (c) 24, (d) 30, and (e) 36 outer stator teeth.

In the analysis of machine characteristics, the proposed asymmetrical-pole PS-DSPM was modeled by the variation of outer stator teeth number based on $12+6 n$ teeth. The two-dimension finite element method simulation was preferred. Firstly, the magnetic flux distribution of the proposed machines was examined to analyze the magnetic flux paths of their configurations. The initial electrical indicators consisting of the magnetic flux-linkage, and back-EMF of these proposed machines were characterized and then, compared with the conventional PS-DSPM. The torque characteristics including the cogging torque, electromagnetic torque, and ripple torque were also investigated to prove the influence on the outer stator teeth number variation under the constraint of the same copper loss when the end-winding is ignored.

\section{RESULTS AND DISCUSSIONS}

\section{III.I Magnetic flux distribution}

The magnetic flux distribution of the cross-section proposed asymmetrical-pole PS-DSPM with 12, 18, 24, 30, and 36 outer stator teeth is indicated in Fig. 2(a)-2(e) when the rotor position is defined, which achieves the positive peak value of the magnetic flux linkage. The distribution of magnetic flux at the outer stator is emphasized in this paper. It is observed that the magnetic flux distribution obtains the symmetrical property for all proposed machines. In addition, the magnetic flux at the outer stator is increasingly distributed due to an increase of the magnetic flux paths when increasing the number of outer stator teeth. These results generally impact on the magnetic flux linkage and back-EMF characteristics. Then, the magnetic flux distribution results will be further utilized for discussing the phase flux linkage and back-EMF topics.

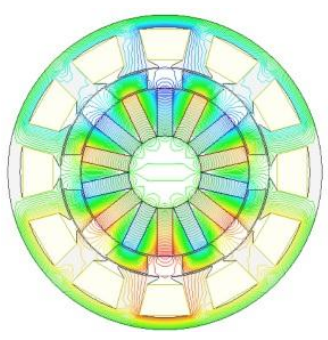

(a)

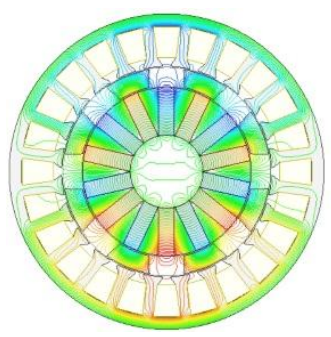

(c)

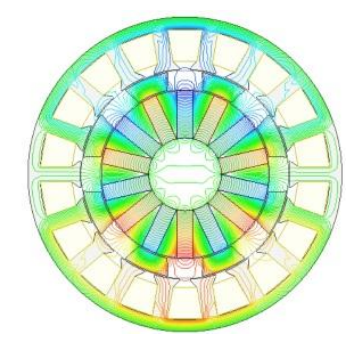

(b)

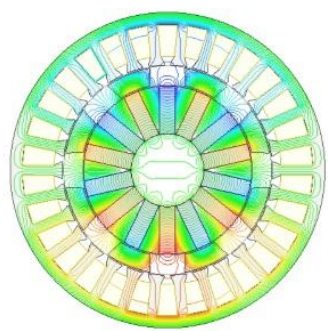

(d)

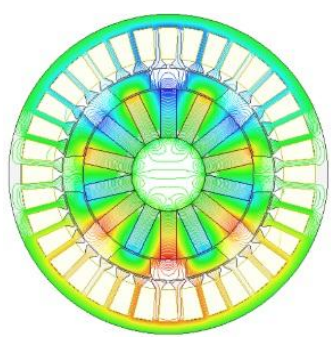

(e)

Fig. 2. The magnetic flux distribution of the asymmetrical-pole PS-DSPM with: (a) 12, (b) 18, (c) 24, (d) 30, and (e) 36 outer stator teeth. 
International Journal of Engineering Research and Technology. ISSN 0974-3154, Volume 13, Number 7 (2020), pp. 1629-1634

(C) International Research Publication House. https://dx.doi.org/10.37624/IJERT/13.7.2020.1629-1634

Table 1. The structural design parameters of the proposed asymmetrical-pole PS-DSPM

\begin{tabular}{|c|c|c|c|c|c|}
\hline \multirow{2}{*}{ Structural parameters (unit) } & \multicolumn{5}{|c|}{ Outer stator teeth ratio $(12+6 n$ teeth, $n=0$ to 4$)$} \\
\hline & $12(n=0)$ & $18(n=1)$ & $24(n=2)$ & $30(n=3)$ & $36(n=4)$ \\
\hline Rotor iron piece number & \multicolumn{5}{|c|}{8} \\
\hline PM number (pieces) & \multicolumn{5}{|c|}{14} \\
\hline Stack length (mm) & \multicolumn{5}{|c|}{25} \\
\hline The number of winding turns & \multicolumn{5}{|c|}{18} \\
\hline Outer radius of outer stator $(\mathrm{mm})$ & \multicolumn{5}{|c|}{45} \\
\hline Inner radius of inner stator (mm) & \multicolumn{5}{|c|}{10.4} \\
\hline Outer air-gap width (mm) & \multicolumn{5}{|c|}{0.5} \\
\hline Inner air-gap width (mm) & \multicolumn{5}{|c|}{0.5} \\
\hline Outer stator tip top length (mm) & \multicolumn{5}{|c|}{0.5} \\
\hline Outer stator tip bottom length (mm) & \multicolumn{5}{|c|}{2} \\
\hline PM thickness (mm) & \multicolumn{5}{|c|}{4.5} \\
\hline Yoke radius of outer stator (mm) & \multicolumn{5}{|c|}{41.5} \\
\hline Inner radius of outer stator (mm) & \multicolumn{5}{|c|}{30} \\
\hline Arc of rotor outer edge (degree) & \multicolumn{5}{|c|}{26} \\
\hline Arc of rotor inner edge (degree) & \multicolumn{5}{|c|}{21} \\
\hline Arc of outer stator teeth (degree) & 13 & 7.85 & 5.55 & 5 & 2.77 \\
\hline Arc of outer stator tip (degree) & 23 & 14.25 & 10.5 & 8.75 & 8 \\
\hline Remanent flux density of Nd-Fe-B (T) & \multicolumn{5}{|c|}{1.2} \\
\hline
\end{tabular}

\section{III.II Phase flux linkage and phase back-EMF}

Fig. 3(a) indicates the open-circuit phase magnetic flux linkage obtained by all proposed asymmetrical-pole PS-DSPM and the conventional PS-DSPM. The positive peak value of the phase flux linkage is concluded in Fig. 3(b). It is observed that the smooth symmetrical waveform of the phase flux linkage is found in all proposed machines as well as the conventional machine. Moreover, the variation of outer stator teeth number results in the change of the phase flux-linkage. The highest magnitude of the phase flux linkage is $27.10 \mathrm{mWb}$ found at the proposed machine having 36 outer stator teeth. The smallest magnitude of the phase flux linkage is $7.85 \mathrm{mWb}$ found at the proposed machine having 12 outer stator teeth. From the results, it is seen that the phase flux linkage is linearly increased with the increase of outer stator teeth number. The description of phase flux linkage variation can be explained by the behavior of the magnetic flux distribution. Normally, the outer stator section is the area of magnetic flux circulation. Due to the increased magnetic flux paths as well as the winding slots when increasing the outer stator teeth number, total magnetic flux circulation through the proposed machine structures is also increased. However, the area of outer stator teeth is importantly beneficial to the manufacture. The proposed asymmetrical-pole machine having 36 outer stator teeth has a smaller area of outer stator teeth than the other proposed machines in this paper, which is resulted in the difficulty of the manufacture due to the weak outer stator structure. Consequently, the 30 outer stator teeth of asymmetrical-pole PS-DSPM provides the high fluxlinkage with the robustness of the outer stator structure.

The open-circuit back-EMF produced by the proposed asymmetrical-pole PS-DSPM having different outer stator teeth number is proposed and also, compared with conventional PS-DSPM, as shown in Fig. 4(a). The positive peak back-EMF of these proposed machines is summarized as illustrated in Fig. 4(b). It is noticed that the phase back-EMF of all proposed machines as well as the conventional machine is asymmetrical waveform because of an unskewed iron rotor piece of salient pole configuration. The highest phase EMF magnitude of 9.15 $\mathrm{V}$ is found at the asymmetrical-pole PS-DSPM having 36 outer stator teeth; following by 30, 24, 18, 12 teeth. Meanwhile, the phase back-EMF magnitude acquired from the conventional PS-DSPM is between that of the proposed machine with 18 and 12 outer stator teeth. In general, the back-EMF induction is depended on the flux linkage motion through outer stator teeth. Furthermore, the increase of outer stator teeth number results in the linear increase of phase back-EMF. This is because the increase of flux linkage movement is obtained from the increased magnetic flux paths at the outer stator teeth, which is 
an enlarge induction area of back-EMF, and the increased winding coil per phase with stator winding slots. From the results, it found that the $18,24,30$, and 36 outer stator teeth of all proposed asymmetrical-pole machines can provide a high range of phase back-EMF. Nevertheless, the proposed machine with 36 outer stator teeth has the weakness of outer stator configuration as mentioned above. So, the asymmetrical-pole PS-DSPM having 30 outer stator teeth is chosen as the suitable outer stator configuration in this paper since it can produce the high phase back-EMF with the structural robustness at the outer stator. The phase back-EMF obtained by this machine is 7.80 $\mathrm{V}$, which is about $43.47 \%$ higher than the conventional PSDSPM. Additionally, the torque characteristics are further demonstrated in all proposed asymmetrical-pole PS-DSPM as well as conventional PS-DSPM.

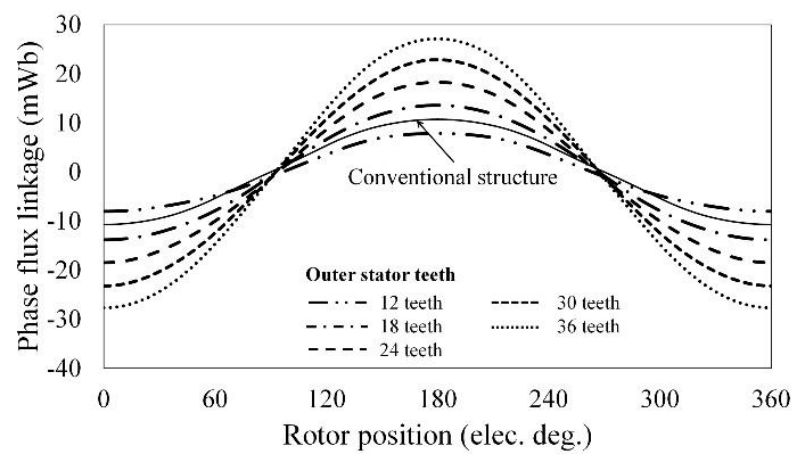

(a)

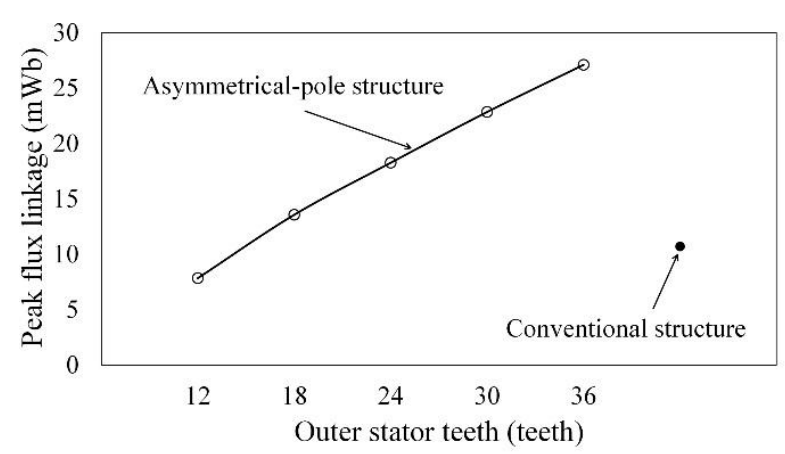

(b)

Fig. 3. The magnetic flux linkage of the proposed asymmetrical-pole PS-DSPM and conventional PS-DSPM: (a) at different rotor positions and (b) peak value of each machine.

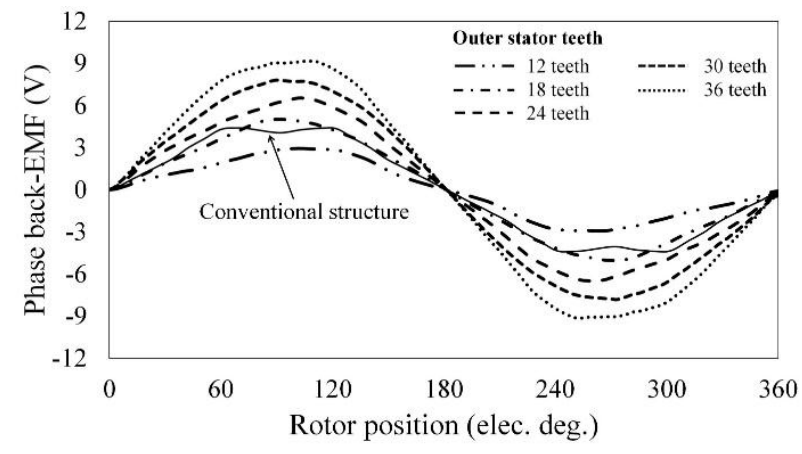

(a)

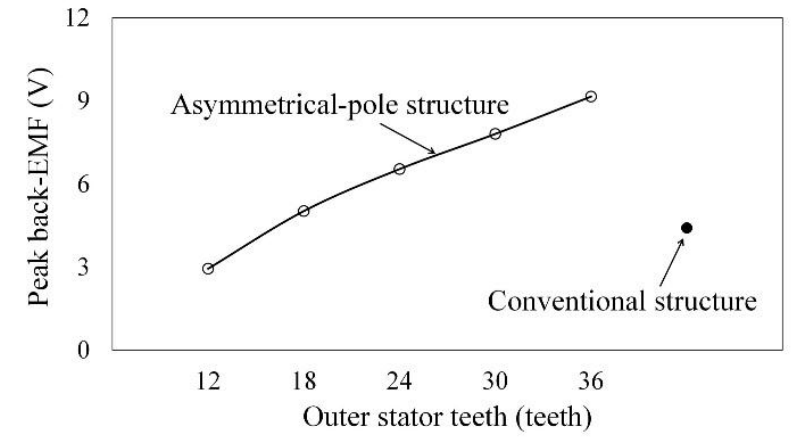

(b)

Fig. 4. The back-EMF of the proposed asymmetrical-pole PSDSPM and conventional PS-DSPM: (a) at different rotor positions and (b) peak value of each machine.

\section{III.III Torque characteristics}

Initial cogging toque of five proposed asymmetrical-pole PSDSPM and conventional PS-DSPM acquired by the starting machine period is given in Fig. 5. It is remarkably observed that the asymmetrical cogging torque waveform is indicated in all proposed machines because the asymmetrical-pole ratio and the relative locations of the winding coil and PMs result in the magnetic flux distortion. However, the proposed machine having 24 outer stator teeth has the highest peak to peak of cogging torque as shown in the dark color line. As a result of the increased magnetic force of this proposed machine between outer stator teeth and rotor iron piece while each particular rotor iron piece is rotated to be fit between the two extreme edges of the particular two outer stator teeth as shown in Fig. 1(c). Especially, the conventional PS-DSPM illustrates a smaller peak to peak of the cogging torque than all proposed machines because it has the lower PM volume affecting the decrease of the magnetic flux density, as given in Table 2. In addition, the electromagnetic torque and ripple torque will be further considered by the characteristic utilization of the initial cogging torque in order to estimate all proposed asymmetrical-pole machines.

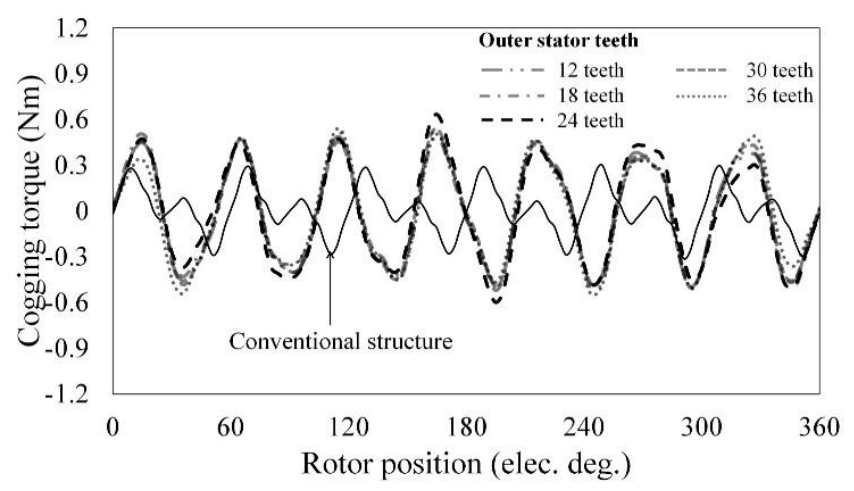

Fig. 5. Initial cogging torque of the proposed asymmetricalpole PS-DSPM and conventional PS-DSPM at various rotor positions. 
International Journal of Engineering Research and Technology. ISSN 0974-3154, Volume 13, Number 7 (2020), pp. $1629-1634$

(C) International Research Publication House. https://dx.doi.org/10.37624/IJERT/13.7.2020.1629-1634

Table 2. Torque characteristics of the proposed asymmetrical-pole PS-DSPM and conventional PS-DSPM

\begin{tabular}{|c|c|c|c|c|c|c|}
\hline \multirow{2}{*}{\begin{tabular}{|l} 
Items \\
Outer stator teeth
\end{tabular}} & \multicolumn{5}{|c|}{ Asymmetrical-pole PS-DSPM } & \multirow{2}{*}{\begin{tabular}{|c|} 
PS-DSPM \\
12
\end{tabular}} \\
\hline & 12 & 18 & 24 & 30 & 36 & \\
\hline Slot packing factor & 0.5 & 0.5 & 0.5 & 0.5 & 0.5 & 1 \\
\hline Copper loss (W) & \multicolumn{6}{|c|}{20} \\
\hline Peck to peck of cogging torque $(\mathrm{Nm})$ & 1.08 & 1.04 & 1.23 & 1.05 & 1.04 & 0.62 \\
\hline Maximum electromagnetic torque (Nm) & 6.62 & 6.86 & 6.75 & 6.39 & 6.41 & 3.77 \\
\hline Minimum electromagnetic torque $(\mathrm{Nm})$ & 4.53 & 4.44 & 4.90 & 5.09 & 5.21 & 3.11 \\
\hline Average electromagnetic torque $(\mathrm{Nm})$ & 5.48 & 5.67 & 5.74 & 5.64 & 5.85 & 3.42 \\
\hline Ripple torque (\%) & 38.12 & 42.61 & 32.18 & 23.17 & 20.37 & 19.17 \\
\hline Volume of PMs $\left(\mathrm{mm}^{3}\right)$ & $21,493.34$ & $21,493.34$ & $21,493.34$ & $21,493.34$ & $21,493.34$ & $20,486.35$ \\
\hline
\end{tabular}

The electromagnetic torque waveform of these proposed machines as well as a conventional machine is illustrated in Fig. 6. Their torque characteristics under the same copper loss are summarized in Table 2. It is remarkably noticed that all proposed asymmetrical-pole PS-DSPM suffer the asymmetric electromagnetic torque profile due to their unsymmetrical EMF and cogging torque waveform. The highest average electromagnetic torque found in the proposed machine with 36 outer stator teeth is $5.85 \mathrm{Nm}$; following by $5.74,5.67,5.64$, and $5.48 \mathrm{Nm}$ found in the proposed machines with $24,18,30$, and 12 outer stator teeth, respectively. As the result, it is seen that all proposed asymmetrical-pole PS-DSPM have a similar value of the average electromagnetic torque. Obviously, the average electromagnetic torque achieved by all proposed machines is higher than conventional PS-DSPM. This is benefited from the higher PM volume and the increased winding slots when the number of outer stator teeth is varied. In addition, the ripple torque of all proposed machines obtained by their torque characteristics is examined in order to verify the suitable outer stator teeth number. From the results, it is found that the proposed asymmetrical-pole machines having 12, 18, and 24 outer stator teeth exhibit large ripple torque as indicated in the light color line. However, the ripple torque produced by the proposed machines having the 30 and 36 outer stator teeth as indicated in the dark color line is approximate to that produced by conventional machine since the back-EMF and cogging torque acquired from these structures are smoother waveforms with symmetric than the other three proposed machines. Consequently, the proposed asymmetrical-pole machine with the 30 outer stator teeth is chosen to be an appropriate outer stator teeth number. This machine can provide the average electromagnetic torque with small ripple torque, which is $39.29 \%$ higher than the conventional PS-DSPM.

Finally, it can be summarized that the PS-DSPM adding the novel asymmetrical-pole ratio is presented. Its particular outer stator teeth number is varied to improve the electromagnetic torque. In our analysis, it is found that the asymmetrical-pole PS-DSPM having 30 outer stator teeth exhibits the high EMF profile with the robustness of the outer stator structure. Particularly, the torque characteristics acquired by this structure illustrate better than the other proposed structure as well as the conventional structure because of the suitable outer stator teeth number. Therefore, the asymmetrical-pole PSDSPM with 30 outer stator teeth is selected as the proposed machine having the suitable outer stator teeth number and becomes another special machine choice for PS-DSPM type.

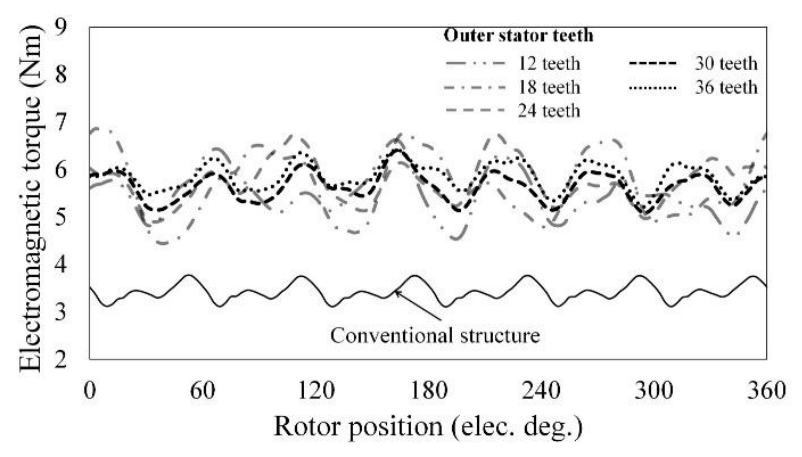

Fig. 6. Electromagnetic torque of the proposed asymmetricalpole PS-DSPM and conventional PS-DSPM at various rotor positions.

\section{CONCLUSION}

In this paper, the novel asymmetrical-pole PS-DSPM structure is proposed with the variation of the outer stator teeth number based on $12+6 n$ teeth for improving electromagnetic performances. The initial electrical machine indicators and the torque characteristics of five proposed asymmetrical-pole PS-DSPM are investigated and then, compared to the conventional PS-DSPM structure. The results show that the variation of outer stator teeth number has firstly an important impact on the increase of the symmetrical magnetic flux distribution. As a consequence, the magnetic flux linkage is enhanced in the proposed machines since both magnetic flux 
paths and winding slots are increased when increasing the outer stator teeth number. Especially, the proposed asymmetricalpole PS-DSPM having 30 outer stator teeth can produce the phase back-EMF with the robust outer stator structure, which is $43.47 \%$ improved from conventional PS-DSPM because of the increase of flux linkage movement through this machine structure. Moreover, the average electromagnetic torque with small ripple torque is produced by this machine is $39.29 \%$ higher than that produced by the conventional structure due mainly to its suitable outer stator teeth number. Hence, the asymmetrical-pole PS-DSPM structure having 30 outer stator teeth is significantly a remarkable choice for the novel electrical machine in the future.

\section{ACKNOWLEDGMENTS}

This work has received a scholarship under the Post-Doctoral Training Program from Khon Kaen University, Thailand (Grant. no. PD2562-18).

\section{REFERENCES}

[1] Zhu ZQ, Howe D. Electrical machines and drives for electric, hybrid, and fuel cell vehicles. Proc. IEEE. 2007;95(4):746-765.

[2] Chau KT, Chan CC, Liu C. Overview of permanentmagnet brushless drives for electric and hybrid electric vehicles. IEEE Trans. Ind. Electron. 2008;55(6): 22462257.

[3] Cheng M, Hua W, Zhang J, Zhao W. Overview of statorpermanent magnet brushless machines. IEEE Trans. Ind. Electron. 2011;58(11):5087-5101.

[4] Zhu ZQ. Switched flux permanent magnet machinesInnovation continues. in Proc. Int. Conf. Elect. Mach. Syst. (ICEMS), Beijing, China. 2011;1-10

[5] Hosseini SM, Agha-Mirsalim M, Mirzaei M. Design, prototyping, and analysis of a low cost axial-flux coreless permanent-magnet generator. IEEE trans. magn. 2008;44(1),75-80.

[6] Wang CX, Boldea I, Nasar SA. Characterization of three phase flux reversal machine as an automotive generator. IEEE Trans. Energy Convers. 2001;16(1):74-80.

[7] Seangwong P, Somchit S, Kaisoda K, Srikhumphun P, Suwanpaiboon K, Sriwannarat W, Siritaratiwat A, Khunkitti P. An Improvement of Electromotive Force in Switched Flux Permanent Magnet Generator by using Multi-Tooth Technique. Inter. Jour. Eng. Res. Tech. 2020;13(3):570-574.

[8] Liao Y, Liang F, Lipo TA. A novel permanent magnet motor with doubly salient structure. IEEE Trans. Ind. Appl. 1995;31(5):1069-1078.

[9] Cheng M, Chau KT, Chan CC. Design and analysis of a new doubly salient permanent magnet motor. IEEE Trans. Magn. 2001;37(4):3012-3020.
[10] Cheng M, Chau KT, Chan CC. Static characteristics of a new doubly salient permanent magnet motor. IEEE Trans. Energy Conv. 2001;16(1):20-25.

[11] Fan Y, Chau KT, Cheng M, A new three-phase doubly salient permanent magnet machine for wind power generation. IEEE Trans. Ind. Appl. 2006;42(1):53-60.

[12] Zhu ZQ, Wu ZZ, Evans DJ, Chu WQ. Novel electrical machines having separate PM excitation stator. IEEE Trans. Magn. 2015;51(4):1-9.

[13] Evans DJ, Zhu ZQ. Novel partitioned stator switched flux permanent magnet machines. IEEE Trans. Magn. 2015;51(1):1-14.

[14] Wang Y, Cheng M, Du Y, Chau KT. Design of hightorquedensity double-stator permanent magnet brushless motors. IET Electr. Power Appl. 2011;5(3):317-323.

[15] Abbasian M, Moallem M, Fahimi B. Double-stator switched reluctance machines (DSSRM): Fundamentals and magnetic force analysis. IEEE Trans. Energy Convers. 2010;25(3):589-597.

[16] Sriwannarat W, Khunkitti P, Janon A, Siritaratiwat A. An Improvement of Magnetic Flux Linkage in Electrical Generator using the novel Permanent Magnet Arrangement. Acta Phys. Pol. A. 2018;133(3):642-644.

[17] Lounthavong V, Sriwannarat W, Siritaratiwat A, Khunkitti P. Optimal Stator Design of Doubly Salient Permanent Magnet Generator for Enhancing the Electromagnetic performance. Energies. 2019;12(16):3201.

[18] Wu ZZ, Zhu ZQ, Shi JT. Novel doubly salient permanent magnet machines with partitioned stator and iron pieces rotor. IEEE Trans. Magn. 2015;51(5): 8105212-8105223.

[19] Sriwannarat W, Lounthavong V, Siritaratiwat A, Khunkitti P. Structural Design of Partitioned Stator Doubly Salient Permanent Magnet Generator for Power Output Improvement. Adv. Mater. Sci. Eng. 2019;2019: 2189761.

[20] Shi JT, Wang AM, Zhu ZQ. Influence of PM-and Armature Winding-Stator Positions on Electromagnetic Performance of Novel Partitioned Stator Permanent Magnet Machines. IEEE Trans. Magn. 2017;53(1)1-12.

[21] Zhu ZQ, Hua H, Wu D, Shi JT, Wu ZZ. Comparative study of partitioned stator machines with different PM excitation stators. IEEE Trans. Ind. Appl. 2016;52(1):199-208.

[22] Fernando N, Saha S. Torsional shear stress minimization techniques and implications on electromagnetic performance of flux-modulated double rotors. IEEE Trans. Energy Convers. 2018;33(1):49-58. 